\title{
Human hepatocellular carcinoma expresses specific PCNA isoforms: an in vivo and in vitro evaluation
}

\author{
Annamaria Venturi ${ }^{1,2}$, Fabrizio Dal Piaz ${ }^{3}$, Catia Giovannini ${ }^{2}$, Laura Gramantieri ${ }^{1,2}$, Pasquale Chieco ${ }^{2}$ \\ and Luigi Bolondi ${ }^{1,2}$
}

Proliferating cell nuclear antigen (PCNA) is a $36 \mathrm{kDa}$ protein involved in several cellular mechanisms, including DNA synthesis and repair, cell cycle regulation and apoptosis. An alteration in PCNA structure might contribute to DNA-damage accumulation in cancer cells. This study was aimed to evaluate the PCNA pattern of expression, in terms of aggregation status, isoforms and post-translational modifications, in human hepatocellular carcinoma (HCC) and cirrhosis as well as in HCC cell lines. Twelve HCCs and surrounding cirrhotic tissues were analysed, along with HepG2, Hep3B and SNU-398 cell lines. Normal liver specimens and cirrhosis without HCC were included as controls. Both DNA-bound and DNA-unbound PCNA fractions were analysed, and PCNA pattern of expression was displayed on two-dimensional gel electrophoresis followed by western blot. Results were confirmed by mass spectrometry. To compare HCCs vs surrounding tissues, immunolabelling and immunostaining were performed. In 6 of $12 \mathrm{HCCs}$ and in cell lines, we found three major PCNA acidic forms, corresponding to monomers, probably dimers and trimers, and a basic isoform. In the six remaining HCCs, only a PCNA acidic form associated with multiple basic isoforms was detected. Importantly, the PCNA basic form was not found in cirrhotic tissues. To clarify the nature of the detected PCNA isoforms, ubiquitin-specific immunoblotting as well as phosphatase treatment were employed. A PCNA-ubiquitylated form in cell lines and PCNA-phosphorylated isoforms in 6 of $12 \mathrm{HCCs}$ were detected. Finally, in the DNA-bound fraction we detected only an acidic PCNA monomeric form. We conclude that human hepatocellular carcinoma expresses specific PCNA isoforms compared to those found in cirrhosis, implicating a role for PCNA functional alterations in hepatocarcinogenesis. Laboratory Investigation (2008) 88, 995-1007; doi:10.1038/labinvest.2008.50; published online 2 June 2008

KEYWORDS: hepatocellular carcinoma; phosphorylation; proliferating cell nuclear antigen; two-dimensional gel electrophoresis; ubiquitylation

Hepatocellular carcinoma (HCC) is one of the most prevalent malignant diseases worldwide, with an increasing incidence expected in the next decades. ${ }^{1}$ Unfortunately, no adequate clinical markers are available for HCC diagnosis and prognosis to date, because $\alpha$-fetoprotein, the serum biomarker routinely used in clinical practice, has a sensitivity of only $50-70 \%{ }^{2}$ Progressive accumulation of DNA-damage has been widely reported in preneoplastic and neoplastic hepatic lesions. ${ }^{3-5}$ However, interindividual variability in human DNA-repair capacity, and in posttranslational modifications of the proteins that activate DNA-damage response pathways, is firmly established, ${ }^{6,7}$ and presents a challenge for using DNA damage as a clinical marker.
The proliferating cell nuclear antigen (PCNA) is a $36 \mathrm{kDa}$ protein with a ring-shaped homotrimeric structure that acts as DNA sliding clamp. Both by p53-dependent and -independent regulations, PCNA interacts with multiple proteins that play a key role in DNA-synthesis and repair, cell cycle regulation, chromatin remodelling and apoptosis. ${ }^{8-12}$ Functionally, PCNA may be present in nucleoplasmic-free/ soluble/DNA-unbound and in detergent-resistant/insoluble/ DNA-bound fractions, the latter tightly associated to chromatin and actively involved in DNA-synthesis and repair. ${ }^{13-15}$ Hence, we considered that detailed evaluation of PCNA may provide insights into hepatocarcinogenesis, and may potentially be of value in clinical evaluation of preneoplastic and neoplastic hepatic lesions.

\footnotetext{
${ }^{1}$ Department of Internal Medicine and Gastroenterology, University of Bologna, Bologna, Italy; ${ }^{2}$ Center for Applied Biomedical Research (CRBA), St Orsola-Malpighi University Hospital, University of Bologna, Bologna, Italy and ${ }^{3}$ Department of Pharmaceutical Sciences, University of Salerno, Fisciano (SA), Italy

Correspondence: Professor L Bolondi, MD, Department of Internal Medicine and Gastroenterology, University of Bologna and Center for Applied Biomedical Research (CRBA), St Orsola-Malpighi University Hospital, University of Bologna, Via Albertoni, 15, 40138 Bologna, Italy.

E-mail: bolondi@med.unibo.it

Received 11 January 2008; accepted 18 March 2008
} 
PCNA functions and interactions are modulated by post-translational regulation, whose exact mechanisms are controversial and not completely understood. Several reports have suggested the existence of PCNA modifications, ${ }^{9,16-18}$ ranging from phosphorylation, ${ }^{10,19,20}$ not confirmed by others' data, ${ }^{21,22}$ to acetylation ${ }^{22}$ and, recently, to methyl esterification. ${ }^{23}$ Additionally, PCNA mono and poly-ubiquitylation in response to DNA damage and sumoylation in the absence of damage was described. ${ }^{24-29}$ Other than forming a homotrimeric structure, PCNA also has been found to form double homotrimeric complexes. ${ }^{30-32}$ As each monomer has specific protein binding sites, the polymeric structure allows PCNA to bind different partners suggesting that the aggregation status may be relevant for its functions.

Altogether, the available evidence emphasizes the importance of a proper PCNA structure, to guarantee an efficient association with binding proteins necessary for regular PCNA function. It is conceivable that, in malignant cells, PCNA structure could undergo modulation in the face of the increased DNA-repair activity required by a high genomic instability. Indeed, in breast cancer a specific PCNA isoform was described, termed cancer-specific PCNA, ${ }^{23,33,34}$ although its functional role is not yet known.

In HCC, PCNA has been found to be overexpressed ${ }^{35}$ and functioning in both DNA duplication and DNA-repair. ${ }^{36}$ To our knowledge, in HCC and cirrhosis, the detailed PCNA pattern of expression has not been investigated. The present study thus aimed to investigate PCNA expression patterns in HCC, in terms of aggregation status, the presence of isoforms and post-translational modifications. We also sought to evaluate the possible use of PCNA specific forms as a clinically useful malignancy related biomarker. This included correlation of PCNA expression patterns with DNA-synthesis and repair activity, by evaluating both the PCNA-soluble and -insoluble/DNA-bound fractions.

To these purposes, we examined Hep3B, HepG2 and SNU-398 HCC cell lines as well as HCC and matched cirrhotic tissues collected at surgery. As controls, normal liver specimens and cirrhosis without HCC were also included.

\section{MATERIALS AND METHODS \\ Patients and Tissue Collection}

HCC and adjacent cirrhotic tissues were collected at surgery from 12 patients subjected to partial hepatectomy for previously untreated HCC ( 8 males: mean age \pm s.d. $=64 \pm 7.4$ years; 4 females: mean age \pm s.d. $=71 \pm 8.4$ years). As controls, a cirrhosis specimen without HCC was obtained after orthotopic liver transplantation and normal liver samplesconfirmed at histopathological examination-were collected after partial hepatectomy for colorectal metastases. Specimens were divided in two parts. One was immediately frozen in liquid nitrogen and stored at $-80^{\circ} \mathrm{C}$. The other was fixed in $10 \%$ formalin and paraffin-embedded for histopathological examination and immunohistochemistry. Informed consent was obtained from each patient prior to surgery. The study protocol conformed to the ethical guidelines of the 1975 Declaration of Helsinki. For each patient, hepatitis B virus (HBV) and hepatitis $\mathrm{C}$ virus (HCV) serum markers were assessed. HBV serum markers were tested by radioimmunoassay test (Abbott commercial kit; Abbott, Chicago, IL, USA). Anti-HCV was tested by second generation ELISA, all positive sera being confirmed by HCV-RNA detection at RT-PCR. Five patients were found to be infected by HBV, five by $\mathrm{HCV}$, one subject was HCV/HBV co-infected and the remaining patient was negative for both viruses. Histopathological grading was assessed according to Edmondson and Steiner criteria. ${ }^{37}$ Liver function was assessed according to Child-Pugh score. Study population's characteristics are reported in Table 1 .

\section{Cell Culture}

Hep3B (HbsAg + , p53-/-) and HepG2 (viruses-, p53 + / +) cell lines (ATCC, Rockville, MD, USA) were maintained in logarithmic growth in minimum essential medium supplemented with 10\% fetal bovine serum (FBS; Sigma-Aldrich, St Louis, MO, USA), $50 \mathrm{IU} / \mathrm{ml}$ sodium penicillin $\mathrm{G}$ and $2 \mathrm{mM}$ L-glutamine. SNU-398 cell line (HbsAg +; ATCC), that displays an heterozygous AGT $\rightarrow$ ATT mutation leading to Ser $\rightarrow$ Ile substitution in p53 gene, was instead maintained in RPMI medium containing $10 \% \mathrm{FBS}, 100 \mathrm{IU} / \mathrm{ml}$ penicillin and $100 \mathrm{U} / \mathrm{ml}$ streptomycin. Once $70 \%$ confluent, cells were rinsed and scraped into ice-cold phosphate-buffered saline prior to pelletting.

\section{Sample Preparation, Sodium Dodecyl Sulphate- Polyacrylamide Gel Electrophoresis, Isoelectrofocusing, 2D-PAGE and Western Blot Analysis}

To perform sodium dodecyl sulphate-polyacrylamide gel electrophoresis (SDS-PAGE), tissue samples were subjected to mechanical pulverization whereas in dry ice, dissolved by repeated syringing in lysis buffer $(10 \mathrm{mM}$ Tris- $\mathrm{HCl} \mathrm{pH}$ 7.4, $2.5 \mathrm{mM} \mathrm{MgCl}_{2}, 0.5 \%$ Triton-X100, $1 \mathrm{mM}$ DTT and protease inhibitors) and centrifuged at 14000 r.p.m. The supernatants were collected and protein extracts were then analysed according to Laemmli. ${ }^{38}$ Briefly, samples were boiled at $95^{\circ}$ for $5 \mathrm{~min}$ in SDS-loading buffer and electrophoresed on a $12 \%$ SDS denaturing gel using Mini Protean apparatus (Bio-Rad Laboratories, Hercules, CA, USA).

For two-dimentional (2D)-PAGE, scraped tissues and cellular pellets were suspended in $1 \mathrm{ml}$ of lysis buffer consisting of $8 \mathrm{M}$ urea, $2 \mathrm{M}$ thiourea, $35 \mathrm{mM}$ Tris, $0.11 \mathrm{M}$ CHAPS, $0.11 \mathrm{M}$ dithioerythritol, $1 \%$ carrier ampholytes, bromophenol blue trace (all by Bio-Rad) and a protease inhibitor cocktail (Roche, Mannheim, Germany) and dissolved by repeated syringing. Homogenates were left in lysis buffer for $1 \mathrm{~h}$ and centrifuged at 14000 r.p.m. Supernatants were collected, reduced and alkylated prior to isoelectrofocusing as previously described ${ }^{39}$ lyophilized, resuspended in rehydration buffer and stored at $-80^{\circ} \mathrm{C}$ until the isoelectrofocusing procedure. To release the DNA-bound/detergent-insoluble 
Table 1 Patient characteristics

\begin{tabular}{|c|c|c|c|c|c|c|c|c|}
\hline Patient & Age (year) & Gender & Virus $^{a}$ & Histo $(\mathrm{G} 1-4)^{\mathrm{b}}$ & Size $^{c}$ & $\operatorname{Nod}^{d}$ & $\mathrm{AFP}^{\mathrm{e}}$ & Child-Pugh $^{f}$ \\
\hline 1 & 68 & $\mathrm{~F}$ & $\mathrm{HCV}$ & G3 & 50 & $U$ & 10 & A5-6 \\
\hline 3 & 72 & M & - & G2-3 & 150 & $U$ & 6 & B7 \\
\hline 4 & 59 & M & $\mathrm{HCV}+\mathrm{HBV}$ & G3 & 23 & $U$ & 72 & A6 \\
\hline 6 & 82 & $\mathrm{~F}$ & $\mathrm{HCV}$ & G3 & 50 & $U$ & 76 & A5 \\
\hline 7 & 62 & $\mathrm{~F}$ & HBV & G3 & 60 & $U$ & $\mathrm{NE}^{\mathrm{g}}$ & A5 \\
\hline 8 & 67 & M & HBV & G3 & 24 & $U$ & 143 & A6 \\
\hline 9 & 62 & M & HBV & G3 & 100 & $U$ & 2 & A5 \\
\hline 10 & 53 & M & HBV & G3 & 40 & M & 29 & A5 \\
\hline
\end{tabular}

avirus: HBV, hepatitis B virus; HCV, hepatitis C virus.

${ }^{b}$ Histo: Histopathological grade according to Edmondson and Steiner criteria. ${ }^{37}$

${ }^{c}$ Size: Size of the HCC nodules analysed in the study, expressed in $\mathrm{mm}$.

${ }^{\mathrm{d}}$ Nodularity: $U$, unifocal; $M$, multifocal.

${ }^{\mathrm{e}}$ AFP: $\alpha$-Fetoprotein serum level, expressed in $\mathrm{ng} / \mathrm{ml}$.

${ }^{\mathrm{f}}$ Child-Pugh: Score evaluating the liver function.

${ }^{\mathrm{g}} \mathrm{NE}$ : Not evaluated.

PCNA fraction, neoplastic and cirrhotic sample pellets were digested with DNAse-I as previously reported. ${ }^{36,40}$ The protein content of dialyzed samples was measured using a protein assay kit according to manufacturer's instructions (Bio-Rad).

Passive rehydration of $7 \mathrm{~cm}, \mathrm{pH}$ 3-10 linear immobilized $\mathrm{pH}$-gradient (IPG) strips (Bio-Rad) was carried out for $12 \mathrm{~h}$ at $20^{\circ} \mathrm{C}$. For cell line samples, available in a most abundant quantity compared to human tissues, in addition to $\mathrm{pH} 3-10$ IPG strips, 7 cm, pH 3.9-5.1 linear IPG strips (Bio-Rad) were also employed, according to the manufacturer's instructions. Isoelectrofocusing was conducted at $20^{\circ} \mathrm{C}$ for $25000 \mathrm{~V}$ hour using a PROTEAN IEF Cell (Bio-Rad). Following isoelectrofocusing, IPG strips were equilibrated for $27 \mathrm{~min}$ by rocking in a $375 \mathrm{mM}$ Tris- $\mathrm{HCl}$ (pH 8.8), $6 \mathrm{M}$ urea, $20 \%$ glycerol and $2 \%$ SDS solution.

The second-dimensional separation was performed in 12\% polyacrylamide gels without SDS using Mini Protean apparatus (Bio-Rad). Molecular weights (MW) were determined by running standard protein markers, covering the range $250-10 \mathrm{kDa}$. From each samples, analysed in triplicate, two gels were obtained. One gel was stained with colloidal Bio-Safe ${ }^{\circledR}$ Coomassie (Bio-Rad) for $24 \mathrm{~h}$ and the other was electrotransferred onto cellulose nitrate membranes overnight at $50 \mathrm{~V}$, using a Mini Trans-Blot system (Bio-Rad). Membranes were then blocked with 5\% non-fatty dry milk in phosphate-buffered saline, washed in phosphate-buffered saline followed by incubation with anti-PCNA monoclonal antibody (clone PC10; Dako, Glostrup, Denmark) opportunely diluted for $90 \mathrm{~min}$ at $37^{\circ} \mathrm{C}$. Proteins were visualized using the enhanced chemiluminescence method (AmershamPharmacia Biotechnology-LKB, Uppsala, Sweden) on photographic slabs (Eastman Kodak, Rochester, NY, USA). The membranes obtained from cell lines samples were then stripped and reprobed overnight with anti-ubiquitin polyclonal antibody (Dako) at $4^{\circ} \mathrm{C}$.

HCC and cirrhotic protein extracts separated on monodimensional SDS-PAGE were subjected to western blot (WB) analysis for PCNA detection, using the same procedure. Additionally, membranes were stripped and reprobed for $2 \mathrm{~h}$ with anti- $\beta$-actin monoclonal antibody (Dako), to rule out differences in protein loading. Digital images of autoradiographies were acquired with Fluor-S Multilmager (Bio-Rad) and band signals were quantified in the linear range of the scanner using a densitometric software (QuantityOne; Bio-Rad). Densitometric readings were calibrated against a reference autoradiography and given in relative density units rounded at 0.5 intervals.

\section{Phosphatase Treatment}

To dephosphorylate proteins extracted from neoplastic tissues and cell lines, protein samples were treated with phosphatase prior to isoelectrofocusing according to the manufacturer's protocol. Briefly, $\lambda$-protein phosphatase 
$(\lambda$-PP) from Upstate (NY, USA) was incubated with protein sample in reaction buffers $(50 \mathrm{mM}$ Tris- $\mathrm{HCl} \mathrm{pH} 7.5,2 \mathrm{mM}$ $\mathrm{MnCl}_{2}, 0.1 \mathrm{mM} \mathrm{Na}_{2}$ EDTA, $5 \mathrm{mM}$ DTT) for $30 \mathrm{~min}$ at $30^{\circ} \mathrm{C}$. The reaction was then stopped with isoelectrofocusing rehydration buffer. As procedure control, $\mathrm{Rb} / \mathrm{pRb}$ was used as a phosphoprotein for measuring the activity of $\lambda$-PP by WB analysis using anti-Rb monoclonal antibody (clone 1F8; LabVision Fremont, CA, USA).

\section{Mass Spectrometry Protein Identification}

2D-PAGE and WB membranes were scanned with a Fluor-S MultiImager (Bio-Rad) and analysed using PD-Quest software, version 7.4 (Bio-Rad). The spots corresponding to PCNA at $\mathrm{WB}$ analysis were excised from the gel with a razor blade and subjected to in situ digestion as previously described, ${ }^{41}$ with some modifications. Briefly, Coomassiestained spots were destained, washed with $100 \mathrm{mM}$ ammonium bicarbonate and acetonitrile (Mallinckrodt Baker, Phillipsburg, NJ, USA), reduced with dithiothreitol and alkylated by iodoacetammide. The gel was incubated for $1 \mathrm{~h}$ at $4{ }^{\circ} \mathrm{C}$ in $50 \mu \mathrm{l}$ of a $12 \mathrm{ng} / \mu \mathrm{l}$ trypsin solution in $50 \mathrm{mM}$ ammonium bicarbonate, $\mathrm{pH}$ 8.0. Then, the supernatant was removed and fresh buffer was added to cover gel pieces during the enzymatic cleavage at $37^{\circ} \mathrm{C}$ overnight. The resulting peptides were extracted first with a 1:1 solution of $25 \mathrm{mM}$ ammonium bicarbonate and acetonitrile and then with a 1:1 solution of $5 \%$ formic acid and acetonitrile. The extracted tryptic peptides were lyophilized and suspended in $10 \mu \mathrm{l}$ of $5 \%$ formic acid liquid chromatography-mass spectrometry (LC-MS) analysis. High-resolution LC-MS and LC-MS/MS analyses were performed on a Q-TOF premier (Waters, Milford, MA, USA) equipped with a nanospray source. Chromatographic separations were performed on an Atlantis capillary $\mathrm{C}_{18}$ column $(10 \times 0.3 \mathrm{~mm}$; Waters $)$ by means of a 50 min linear gradient from $10-50 \% \mathrm{CH}_{3} \mathrm{CN}$ in $1 \%$ formic acid, $0.1 \%$ TFA. Mass spectra were acquired on a $500-1800 \mathrm{~m} / \mathrm{z}$ range. The ESI Q-TOF accuracy was calibrated by the external calibration of Glu-Fib (3 p.p.m.). The applied spray voltage was $800-1000 \mathrm{~V}$, with a sample cone of $25-40 \mathrm{~V}$. The MCP detector was at $2250 \mathrm{~V}$, and the energy adjustable collision cell was filled with pure argon gas. MS/MS data processing involved the use of MassLynx 3.5 and data were searched in the NCBInr protein sequence databases using the MS/MS ion search program MASCOT (http://www. matrixscience.com). To obtain the protein identification, peptide had to be in the top hit, with more than two peptide sequences matched. Under less-than-optimal circumstances, a matched protein was accepted if it ranked as the top hit with a single peptide match. In this case (only 4 identities), the MS/MS fragment ion pattern was verified by manual inspection. The manual inspection of MS/MS data processing involved use of the Peptide Sequencing Program with the following strict criteria: (1) MM tolerance was set at $0.3 \mathrm{Da}$ and mass type was assumed to be monoisotopic; (2) the peak threshold was $0.15 \%$ and the fragment ion tolerance
$0.15 \mathrm{Da}$; (3) nearly complete Y-ion series and partial complementary B-ion series needed to be present and the Y-ions should correspond to peaks with relatively high intensity.

\section{PCNA Immunohistochemical Assessement}

From HCC and surrounding cirrhosis samples, $4-\mu \mathrm{m}$-thin sections were cut, collected on 3-ethoxy-aminoethyl-silane treated slides and allowed to dry overnight at $37^{\circ} \mathrm{C}$. Before immunostaining, sections were microwaved in $10 \mathrm{mM}$ citrate buffer solution $\mathrm{pH} 6.0$ for $20 \mathrm{~min}$ at $750 \mathrm{~W}$. After cooling down at room temperature, slides were incubated for $1 \mathrm{~h}$ at room temperature with the primary anti-PCNA antibody (clone PC10; Dako) opportunely diluted. The reaction was developed according to a streptavidin-biotin-peroxidase preformed complex (EnVision; Dako) and evidentiated using a peroxidase/DAB enzymatic reaction.

Staining of sections was assessed on 10 consecutive $\times 20$ magnification fields by two independent observers (AV, CG) using a validated semiquantitative scale where + is staining of $<5 \%$ hepatocytes; ++ , staining of $5-30 \%$ hepatocytes and +++ staining on $>30 \%$ hepatocytes.

\section{RESULTS}

\section{D-PAGE/WB Analysis-Hepatocellular Carcinoma}

In HCC samples, 2D-PAGE (Figure 1) coupled with WB analysis revealed the existence of two main different PCNA expression patterns. In the first one (hereafter referred to as pattern 1), detected in all the three cell lines and in 6 of 12 HCCs, three major acidic PCNA forms and a basic isoform were visualized (Figures 2, 3a and 4, left side).

The main acidic forms, as suggested by MW, correspond to PCNA monomers $(36 \mathrm{kDa})$, and probably dimers $(75 \mathrm{kDa})$ and trimers $(110 \mathrm{kDa})$, because the PCNA dimeric and trimeric structures were stable enough to survive even during isoelectrofocusing and 2D-PAGE processes. ${ }^{42}$ In cell lines (Figures 2 and 3a), a high MW form $(220 \mathrm{kDa})$ was detected at the same acidic pI, probably corresponding to the double trimeric PCNA structure. The spots observed at low MW in both HepG2 and Hep3B cells (near 30, 23 and $15 \mathrm{kDa}$ ), could result from PCNA proteolytic degradation (Figure $2 \mathrm{~b}$ and $\mathrm{d}$ ).

The PCNA spots at $36 \mathrm{kDa}$ were actually a cluster of several forms ranging from pI 4.5 to pI 4.65. Possibly depending on higher sample homogeneity, this aspect was more evident in cell lines in which, as confirmed by using narrow $\mathrm{pH}$ range IPG strips to increase resolution (Figure 2, right side), at least 12 forms were evident ( $\mathrm{pI} 4-4.7$ ). These different isoforms may probably be the expression of a post-translational modification. After $\lambda$-PP treatment, performed to release phosphate groups from phosphoamino acid residues, no modifications were detected, suggesting that the observed isoforms were not due to a phosphorylation process (Figure 3b).

The basic isoform detected in these samples displayed a significantly high pI (=9), with the same MW of PCNA monomer (Figures 2, 3a and 4, left side). In only one HCC 

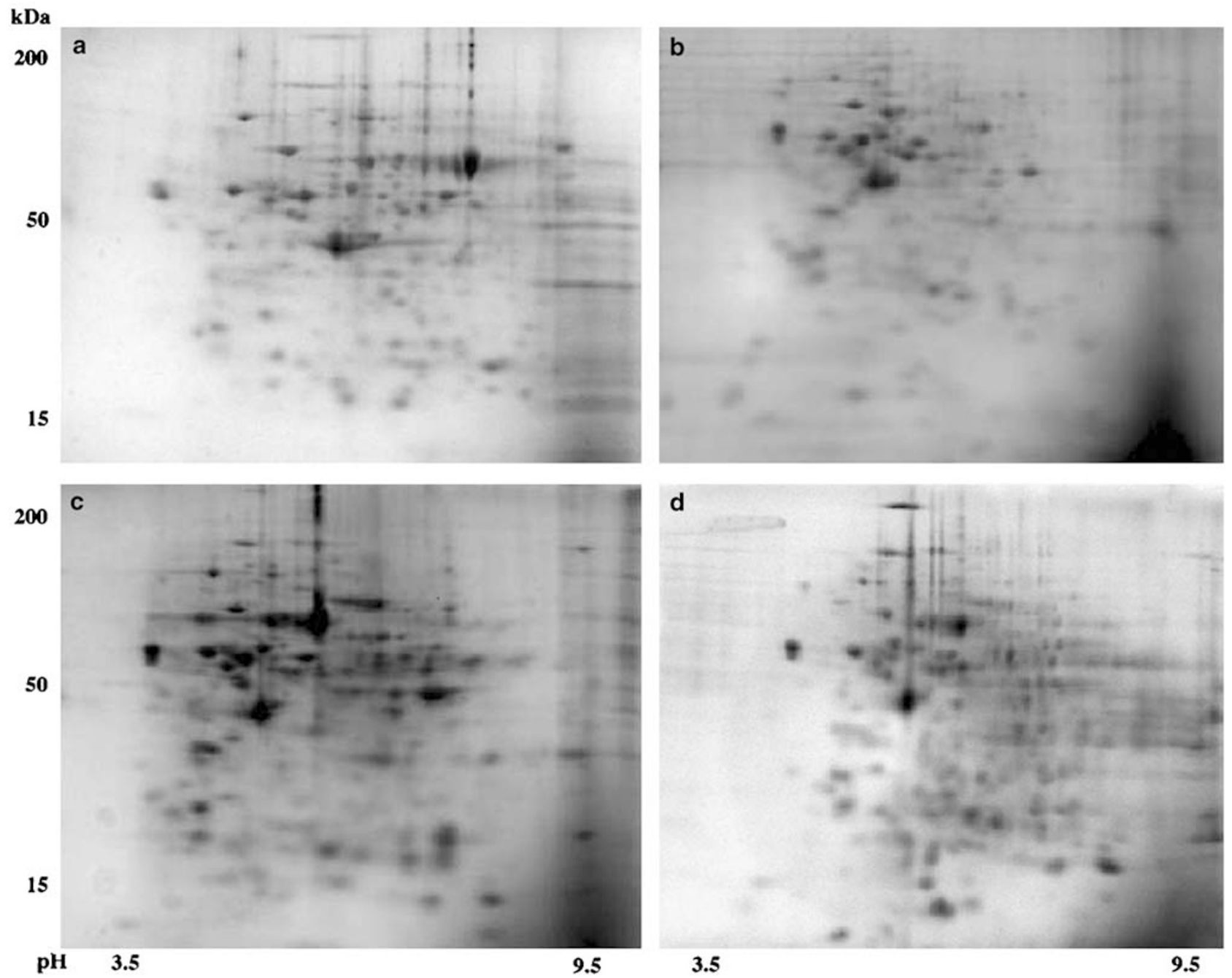

Figure 1 Representative Coomassie-stained 2D maps of the total sample extracts. Up to $1 \mathrm{mg}$ of proteins extracted from liver cell lines (a: HepG2, b: Hep3B) and tissue specimens (c: hepatocarcinoma, d: cirrhosis) were separated by 2D-PAGE (first dimension, pH 3-10 linear, $7 \mathrm{~cm}$ IPG strips; second dimension, $12 \%$ homemade polyacrylamide gels without SDS).

(Figure $4 \mathrm{~b}$ ), the basic isoform showed a higher MW, near $80 \mathrm{kDa}$. In five of six tissue samples and in cell lines, it may be possible that the basic isoform was the expression of a high methyl esterification process, that indeed dramatically shifts proteins to basic $\mathrm{pI}$, occurred in the monomeric form. Another post-translational change involving the dimeric form may explain the basic spot observed in the remaining HCC (Figure 4b).

In HepG2, Hep3B and SNU-398 cell lines, PCNA was present in multiple other modified forms, not detectable in tissue samples (Figures 2 and 3a). To gain a better understanding of these findings, ubiquitin-specific immunoblotting was performed, detecting a PCNA-ubiquitylated isoform at $42 \mathrm{kDa}$. The same spot was indeed stained by both antiPCNA and anti-ubiquitin antibodies (Figure $3 a$ and c).

In the six remaining HCCs, we identified a different PCNA migration pattern (hereafter referred to as pattern 2), not detected in cell lines. Actually, only a PCNA monomeric acidic form was detected in association with several basic isoforms (Figure 4, right panel). Some samples showed the monomeric structure coupled with a more acidic satellite spot (Figure $4 \mathrm{~d}$ and e). The PCNA basic isoforms comprised a heterogeneous population of molecules, ranging from 2 (Figure 4c) to 7 (Figure $4 \mathrm{f}$ ), with $\mathrm{MW}$ of $45 \mathrm{kDa}$ and $\mathrm{pI}$ ranging from 7 to 7.5. Interestingly, these spots disappeared or seemed to shift to basic spots when protein extracts were incubated with $\lambda$-PP, indicating that these isoforms were caused by a phosphorylation process (Figure $3 \mathrm{~d}$ and e). To verify the efficacy of $\lambda$-PP treatment, $\mathrm{Rb} / \mathrm{pRb}$ were used as control (Supplementary Figure 1).

No statistically significant correlation was found between PCNA isoform pattern of expression in HCCs and a number of clinical-pathological tumour-related variables, including patient's age, viral status, histopathological grade, ChildPugh score, tumour size or PCNA immunostaining (data not shown). Although the two samples with higher $\alpha$-fetoprotein 



Figure 2 2D-PAGE/western blot analysis. Protein migration of PCNA from Hep3B and HepG2 cell lines. (a, b) HepG2; (c, d) Hep3B. Monomeric, probably dimeric, trimeric and double trimeric forms associated with a basic isoform of PCNA were detected. A PCNA ubiquitylated form was also found (b, d, arrows). Some spots smaller than PCNA monomer, probably resulting from PCNA proteolytic degradation were visualized (b, d, arrowheads).

serum levels displayed PCNA expression pattern 1, no correlation was found between PCNA expression patterns and levels of $\alpha$-fetoprotein, the only HCC biomarker used in clinical practice. This finding was also supported by the evidence that the analysed cell lines displayed the same PCNA expression pattern but very different $\alpha$-fetoprotein levels.

\section{D-PAGE/WB Analysis-Cirrhosis}

Among cirrhotic tissues surrounding HCC (Figure 5), 10 of 12 cases displayed only an acidic spot (pI 4.5) corresponding to PCNA at $36 \mathrm{kDa}$ (Figure $5 \mathrm{a}$ ). In one sample, a more acidic satellite spot was visualized close to the monomeric PCNA form at the same MW (Figure 5b). In the remaining sample, PCNA monomeric, probably dimeric and trimeric, forms were detected, without evidence of modified isoforms (Figure 5c). In addition, the cirrhotic sample without HCC, used as control, displayed only the PCNA monomeric form (Figure 5d). In none of cirrhotic specimens was a basic PCNA form was demonstrated. Among normal liver samples used as controls (Figure 6), one displayed only an acidic spot (pI 4.5) corresponding to PCNA at $36 \mathrm{kDa}$ (Figure 6a), whereas in the other probably a dimeric form was additionally detected (Figure 6b).

\section{D-PAGE/WB Analysis-PCNA DNA-Bound Fraction}

After DNAse-I treatment, only an acidic PCNA form was visualized (Figure 7), corresponding to the monomer at $36 \mathrm{kDa}$, pI 4.5. This finding was demonstrated in all the three cell lines (Figure 7a) and in 7 of 12 HCCs (Figure 7b), in which a proliferative and/or repair activity was ongoing, as the detection of both nucleoplasmic-free/soluble/DNAunbound and detergent-resistant/insoluble/DNA-bound fractions suggests. Among these seven cases, four showed PCNA expression pattern 1 and the remaining three displayed pattern 2 as PCNA-soluble fraction. In the remaining HCCs, as well as in all the cirrhosis specimens, no DNA-bound PCNA fraction was detected after DNAse-I treatment.

\section{Mass Spectrometry Data}

To further confirm the identity of PCNA protein spots visualized by $\mathrm{WB}$, mass spectrometry analyses were carried out. In these experiments, $4-7$ peptides of PCNA sequence were 



kDa
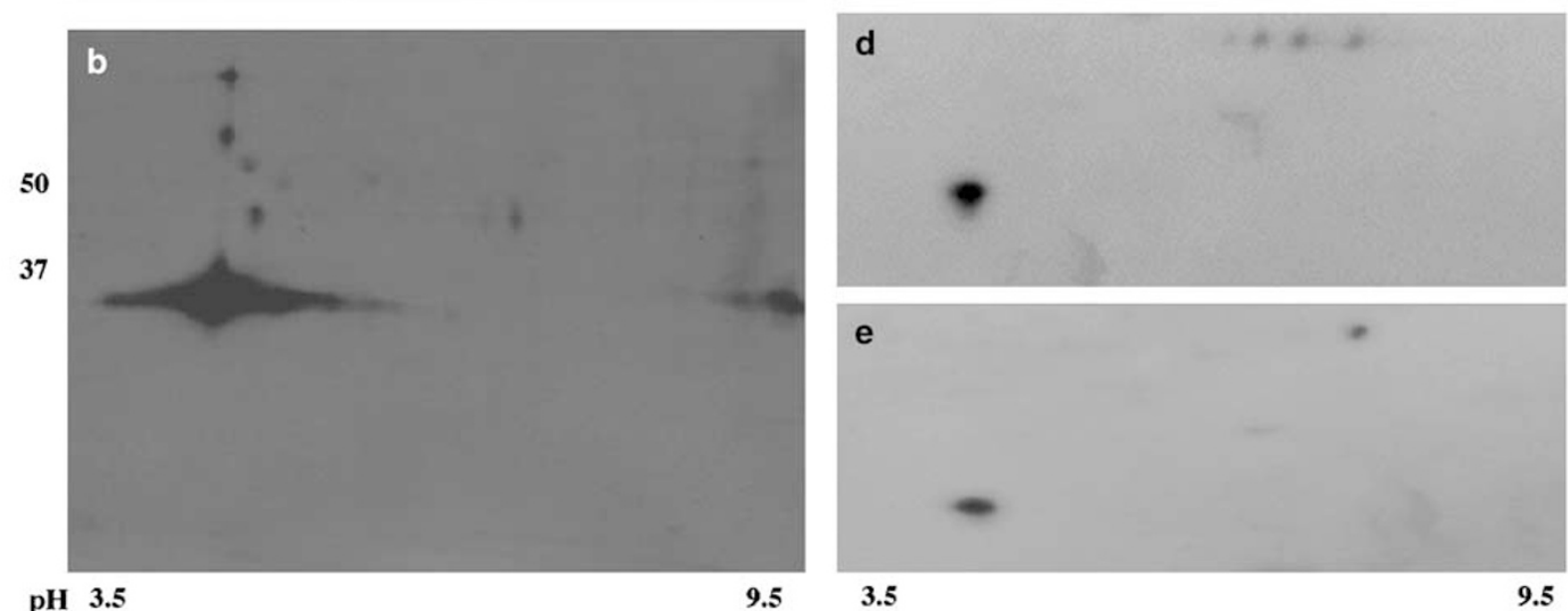

45

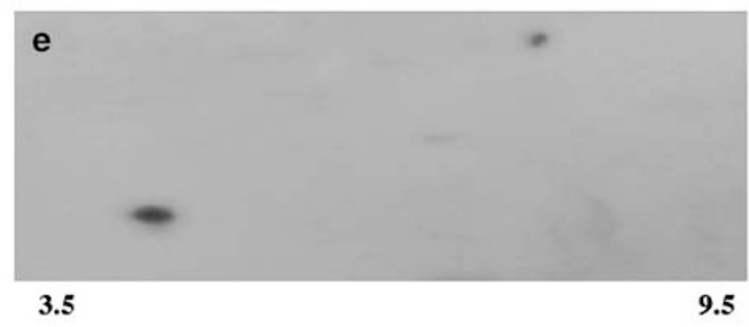

Figure 3 2D-PAGE/western blot (WB) analysis. PCNA post-translational modifications. (a-c) SNU-398 cell line. 2D-PAGE from SNU-398 cell line was analysed by WB using either anti-PCNA (a) or ubiquitin-specific antibody (c) by stripping and reprobing. In addition to PCNA monomeric, probably dimeric, trimeric and double trimeric forms associated with a basic isoform, a PCNA ubiquitylated form was also found (arrows). (b) A SNU-398 cell sample dephosphorylated prior to 2D-PAGE. No remarkable modification of PCNA pattern of expression was observed. Untreated (d) and dephosphorylated (e) HCC sample showing PCNA expression pattern 2. After $\lambda$-protein phosphatase treatment PCNA basic isoforms disappeared or seemed to shift to basic spot, indicating that isoforms were caused by a phosphorylation process.

identified (Table 2) and the differences between experimental and theoretical MW of the identified peptides were less then 50 p.p.m. Positive MS PCNA identifications were achieved, analysing both acidic and basic isoforms. In particular, spots at $36 \mathrm{kDa}$ pI 4.5, 4.6 and 9, at 75, 110 and $220 \mathrm{kDa}$ pI 4.5 , at $45 \mathrm{kDa}$ pI 7.2 were identified as PCNA. In all the cases, the obtained results led to a sequence coverage ranging from 15 to $28 \%$, satisfactory to achieve an unambiguous protein identification, but lacking of many structural information. A representative PCNA peptide identified is shown in Figure 8.

\section{WB Analysis And Immunohistochemistry}

PCNA expression of the cancerous and surrounding cirrhotic liver was determined by immunoblotting, resulting in specific bands corresponding to $36 \mathrm{kDa}$. In each case the integrated optical density values were standardized with those of $\beta$-actin. PCNA resulted to be upregulated in 9 of 12 HCCs and downregulated in the remaining HCCs compared to matched cirrhosis (Figure 9). However, no statistically significant relationship was found between PCNA levels in HCCs and cirrhotic tissues $(P=0.17$ at $t$-test for independent samples) or between PCNA protein level in HCCs showing PCNA patterns of expression 1 or $2(P=0.6$ at $t$-test for independent samples; Figure 10). From these results we can rule out the possibility that PCNA expression pattern is related to different total PCNA amount.

PCNA immunostaining in cancerous and surrounding cirrhotic liver (Figure 9) was selectively localized in the nucleus and mostly in hepatocytes, with few cases showing a faint positivity in fibroblast and biliocytes. According to the semiquantitative scale used, 9 of 12 HCCs showed +++ PCNA immunostaining, 2 cases displayed ++ immunostaining and the remaining only + . HCCs displaying PCNA expression patterns 1 and 2 showed a similar PCNA immunostaining (Figure 9). 

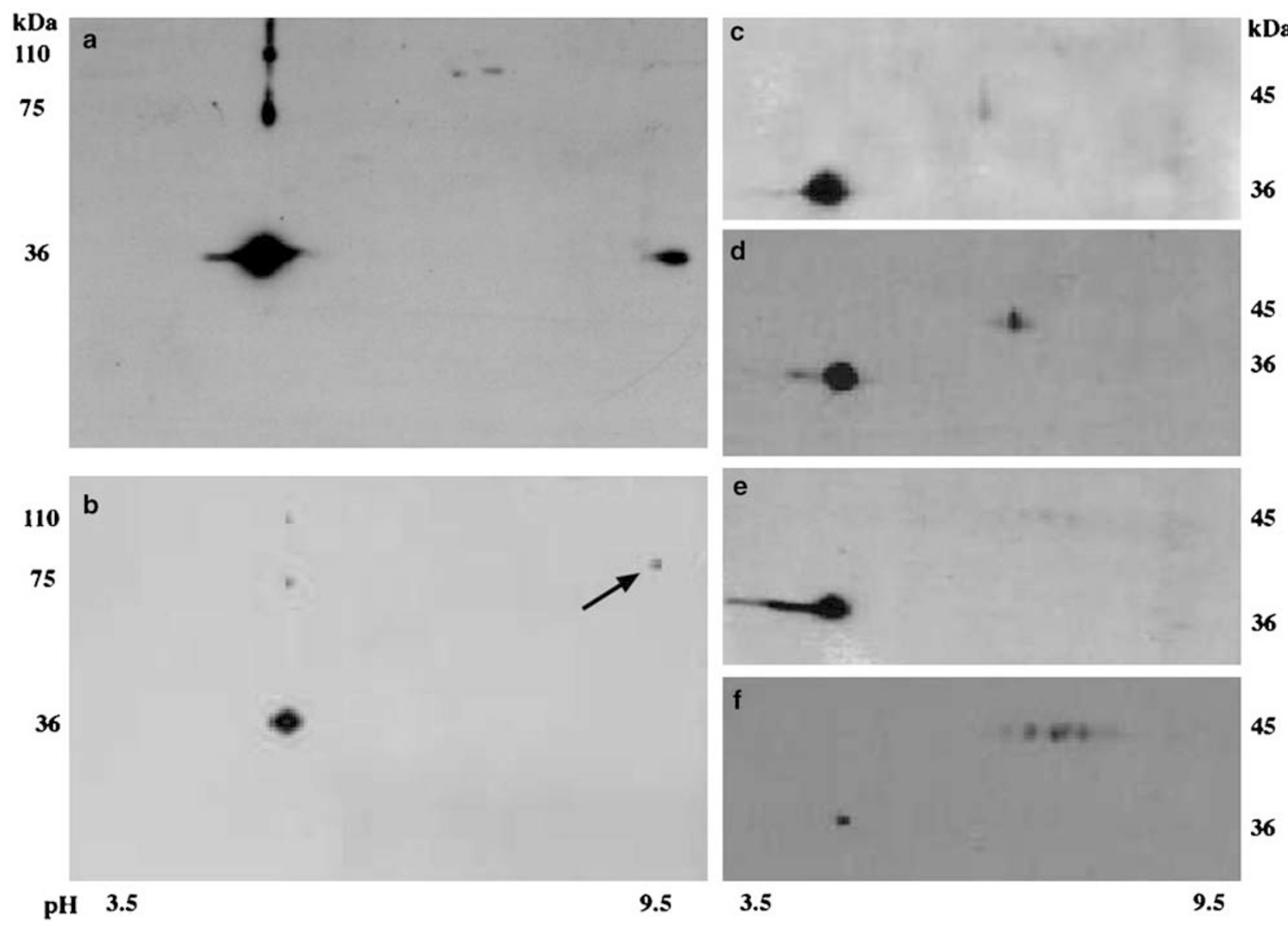

Figure 4 Western blot analysis. Protein migration of PCNA from human HCC tissue specimen. Left side: PCNA expression pattern 1, displayed by 6 of 12 HCCs. (a) Monomeric, probably dimeric and trimeric forms and a basic isoform of PCNA were demonstrated. (b) PCNA basic isoform detected at higher molecular weight (arrow) in one HCC sample. Right side: PCNA expression pattern 2 detected in the remaining neoplastic tissue samples.

A monomeric acidic PCNA form was associated with several basic isoform, ranging from 2 (c) to 7 (f).

\section{DISCUSSION}

The detection of multiple PCNA isoforms is not a new finding, $9,10,15-20$ and post-translational modification is widely thought to be implicated in modulating its function and/or termination of function, in promoting or disrupting protein/ protein interactions and in guiding PCNA to correct partner protein at the correct time. In the present study we analysed, to our knowledge for the first time, PCNA expression in human HCC and cirrhosis in terms of aggregation status, isoforms and post-translational modifications, by using 2D-PAGE/WB and LC-MS. To compare each patient's HCC and cirrhotic tissue, and to investigate as to whether the PCNA patterns of expression may be related to total PCNA protein amount or to different cell types in the tissues, immunolabelling and immunostaining were also performed. As PCNA is regulated through a p53-dependent and independent pathway, ${ }^{43}$ HepG2, Hep3B and SNU-398 cell lines were selected to analyse cells with different p53-status. Using this approach, we identified two different PCNA migration patterns and we clearly detected acidic as well as basic PCNA isoforms, according to previous reports. ${ }^{6,42}$ Most notably, isoforms having a basic pI were exclusively found in malignant cells. The PCNA basic isoforms, exclusively detected in hepatic malignant samples, may represent a new signature for neoplastic liver cells compared to cirrhotic tissues.

PCNA isoforms probably do not depend on p53 status, because we obtained similar findings in all the three cell lines despite their different p53 status. Furthermore, different PCNA appearances in cancerous and cirrhotic samples cannot be due to the 2D-PAGE's basic and oxidizing conditions, because all samples were analysed in the same setting, and each in triplicate. We furthermore do not consider that PCNA appearance can be due to artefactual aspects, because cirrhotic or control samples did not display the isoforms detected in HCC and confirmed as PCNA by MS analyses, strongly suggesting a pattern of expression related to the neoplastic transformation. PCNA immunolabelling and immunostaining results also rule out the possibility that PCNA expression pattern is related to different total PCNA protein amount. Additionally, some of the detected forms were close 
kDa

36

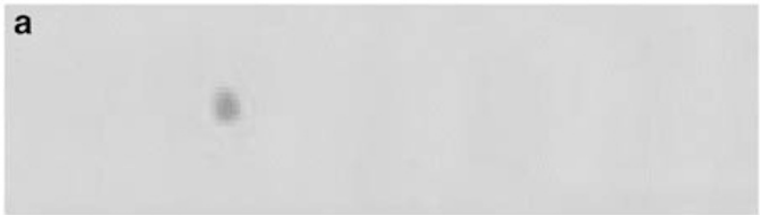

36

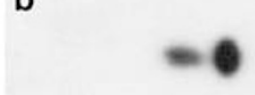

C

110

75

36
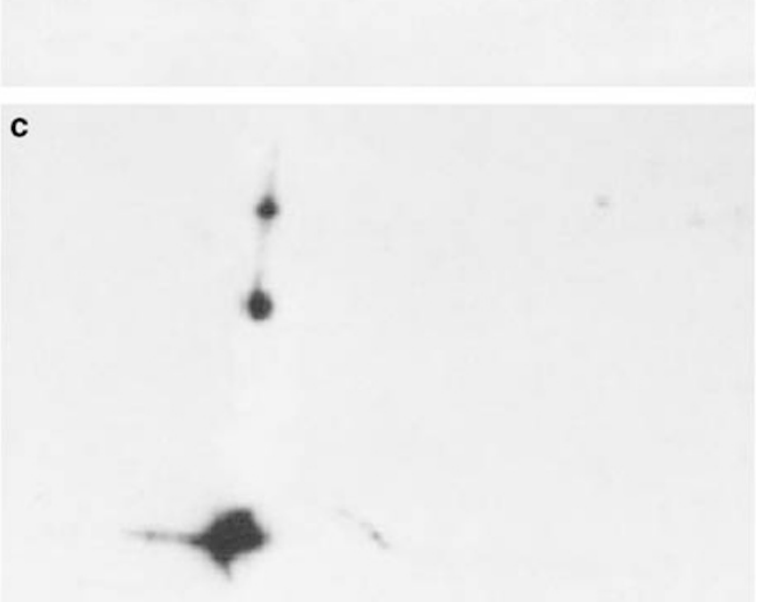

36

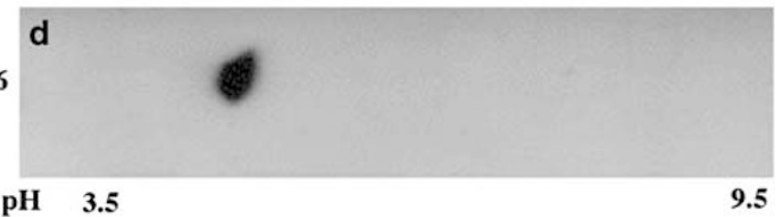

Figure 5 Western blot analysis. PCNA protein migration in cirrhotic tissue samples. (a) In 10 of 12 cirrhotic samples as well as in the cirrhotic specimen without HCC (d) used as control only an acid monomeric PCNA form was visualized at $36 \mathrm{kDa}$. (b) A more acidic PCNA satellite spot was present in one cirrhotic sample. (c) Probably monomeric, dimeric and trimeric acidic PCNA forms were detected in one cirrhotic specimen.

to the PCNA isoforms previously described. ${ }^{33,42}$ Similar comments can be made about PCNA aggregation status (more clear in Supplementary Figure 2, when different antibody dilution and exposure times were employed). Indeed, several reports demonstrate that PCNA trimeric structure is stable both on DNA and in solution. ${ }^{44,45}$ Additionally, PCNA was previously detected as dimer and trimer on 2D SDS-PAGE ${ }^{42}$ and, more recently, double trimeric structure was described. ${ }^{31,32}$ Our findings therefore agree with those reported in the literature.

As we hypothesized the presence of PCNA post-translational modifications, we studied in more detail the isoforms detected in neoplastic specimens. In particular, by a specific ubiquitin immunoblotting, we detected a ubiquitylated PCNA isoform in cell lines. Accumulating lines of evidence suggest that ubiquitylation plays a role in the regulation of
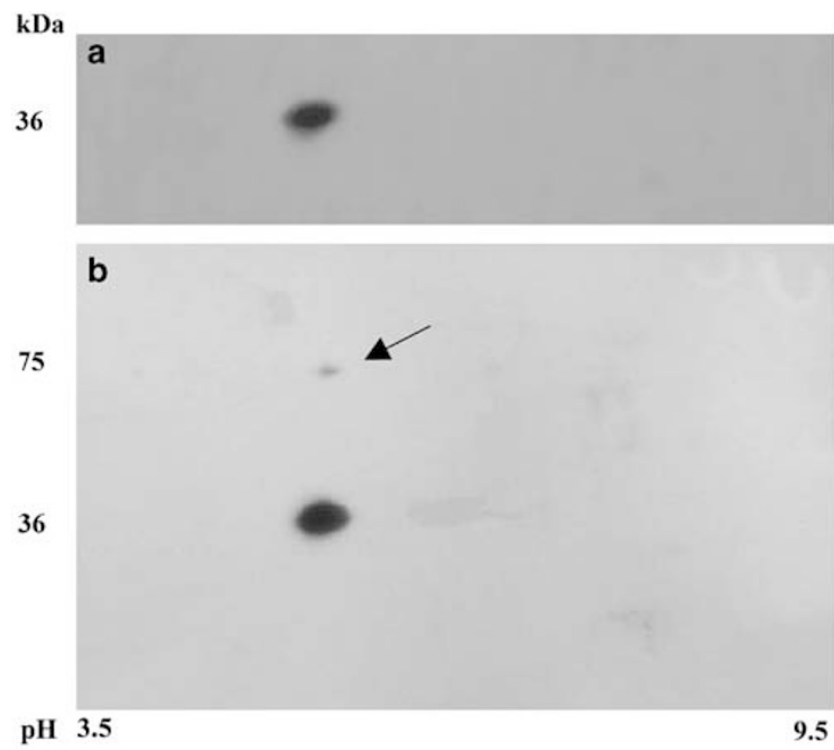

Figure 6 2D-PAGE/western blot analysis. Normal liver samples. (a) One normal liver specimen used as control displayed the acid monomeric PCNA form at $36 \mathrm{kDa}$. (b) In the other normal liver tissue, in addition to PCNA acidic monomeric form, a probably dimeric form was detected (arrow).

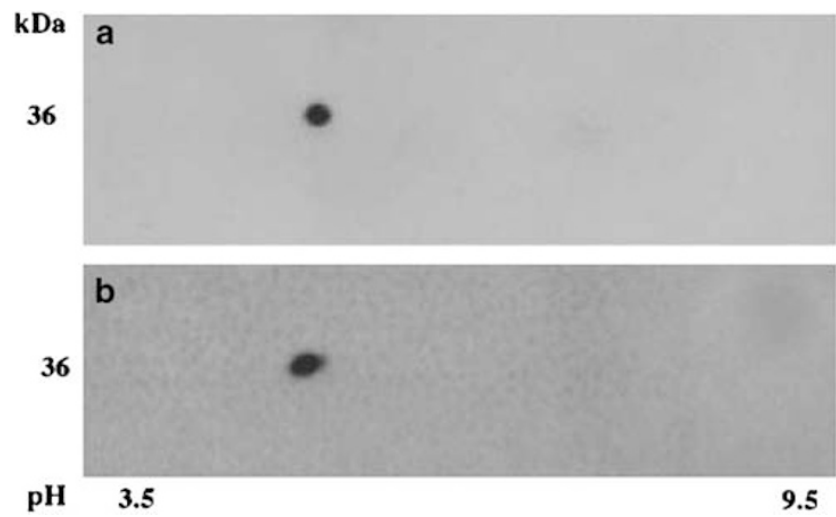

Figure 7 Western blot analysis after DNAse-I treatment. After DNAse-I treatment only an acidic monomeric PCNA form was detected both in cell lines (a) as well as in tissue specimen (b).

PCNA functions. ${ }^{24-29}$ Ubiquitylation has indeed emerged as an important regulatory switch during DNA replication, and the DNA-damage response specifically involves postreplication DNA repair acting as an error-prone replication safeguard mechanism. ${ }^{46}$ Alternatively, mono-ubiquitylation may prevent binding of replication factors to PCNA. ${ }^{26}$ In a nonmutually exclusive fashion, such mono-ubiquitylation may attract specific binding partners due to the presence of specific binding motifs. Whatever the exact mechanism, it is interesting to note that PCNA ubiquitylation is conserved from yeast to mammals, suggesting that the functional consequences of this modification might be conserved as well. In HCC cell lines, it is conceivable that the PCNA ubiquitylated 


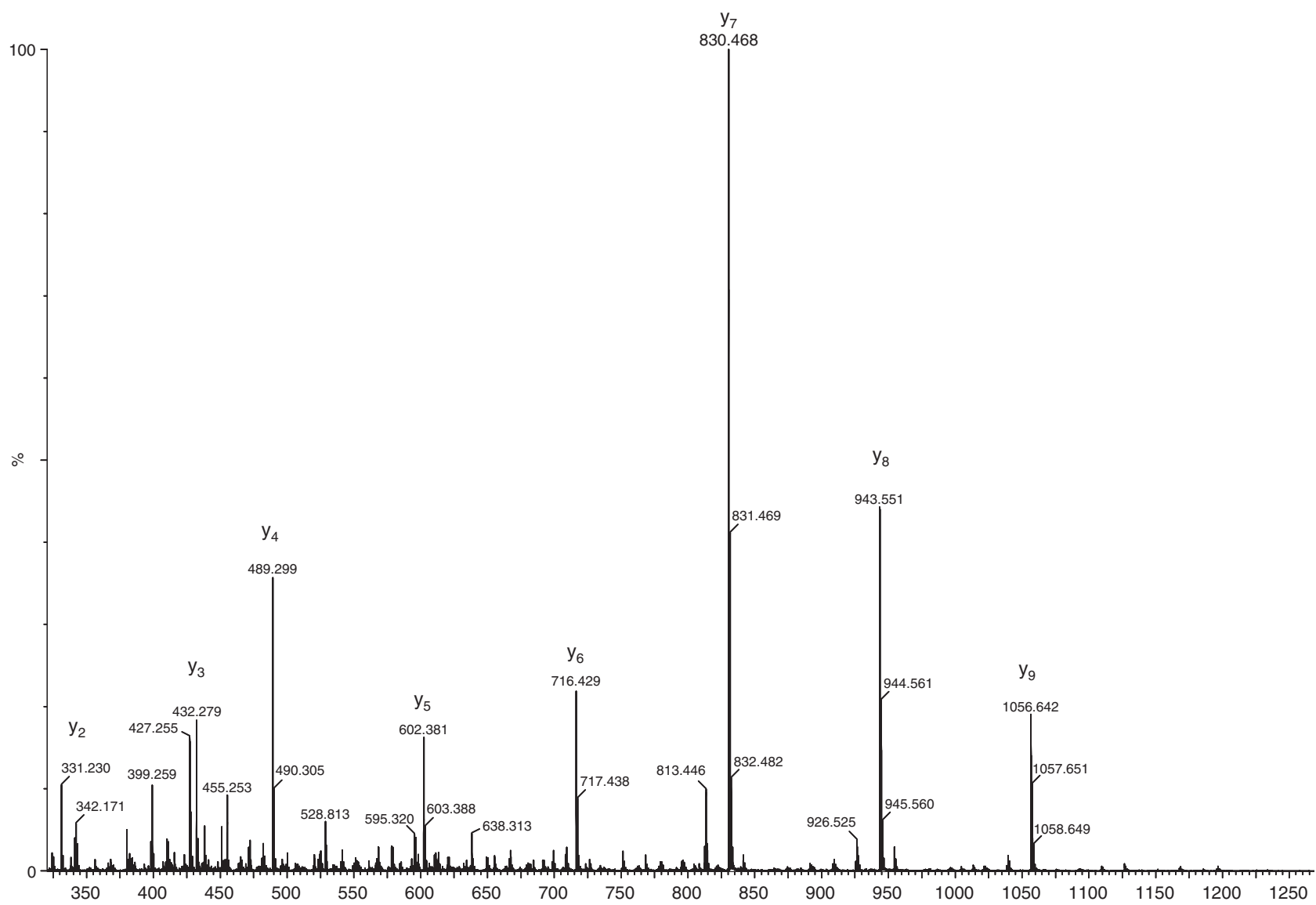

Figure 8 Identification of PCNA from 2D-PAGE by matrix-assisted laser-desorption ionisation time of flight protein characterization. MS/MS spectrum of the doubly charged parent ion at $\mathrm{m} / \mathrm{z}$ 631.309. Fragments belonging to the $y$ series are indicated.

Table 2 PCNA peptides identified by LC-MS/MS analysis following in gel digestions

\begin{tabular}{lcc}
\hline Experimental MW & Peptide & Theoretical MW \\
\hline 856536 & $6-13$ & 856538 \\
671453 & $15-20$ & 671422 \\
1260605 & $81-91$ & 1260613 \\
2074016 & $92-110$ & 2073985 \\
1583843 & $150-164$ & 1583798 \\
883499 & $241-248$ & 883458 \\
777305 & $255-261$ & 777303 \\
\hline
\end{tabular}

${ }^{\mathrm{a}}$ Theoretical MW: Theoretical masses of the identified peptides.

form could a pivotal response to the increased DNA repair activity required by high genomic instability and the accumulating DNA-damage in cancer cells. As previously suggested, ${ }^{42}$ the detection of a ubiquitylated PCNA isoform may also explain the low MW spots observed in both HepG2 and Hep3B cells as possibly results of PCNA ubiquitin depending proteolytic degradation.
To study more in detail the other isoforms detected in neoplastic specimens, we performed a phosphatase treatment of the samples. In particular, we utilized $\lambda$-PP because it acts on all currently known phosphoamino acid residues such as phosphoserine, phosphothreonine, phosphotyrosine and phosphohistidine. ${ }^{47}$ We detected PCNA phosphorylated isoforms in HCCs showing PCNA expression pattern 2. In the remaining samples, no effect of the treatment was observed. The several PCNA isoforms detected in neoplastic samples compared to non-cancerous tissues might help explain the PCNA overexpression in HCC detected at immunolabelling and immunostaining analysis, and agrees with literature data. ${ }^{35}$

Theoretically, a primary role of phosphorylation is to act as a switch to turn 'on' or 'off' a protein activity or a cellular pathway in an acute and reversible manner. ${ }^{48}$ Regarding PCNA in particular, it was recently demonstrated ${ }^{20}$ that phosphorylation stabilizes the functional PCNA form during DNA synthesis. As post-translational modifications were demonstrated, it was theoretically possible that such modifications could mask an epitope affecting the PCNA-antibody interaction. However, when two different antibodies against PCNA were employed in a previous study for $2 \mathrm{D}$ 

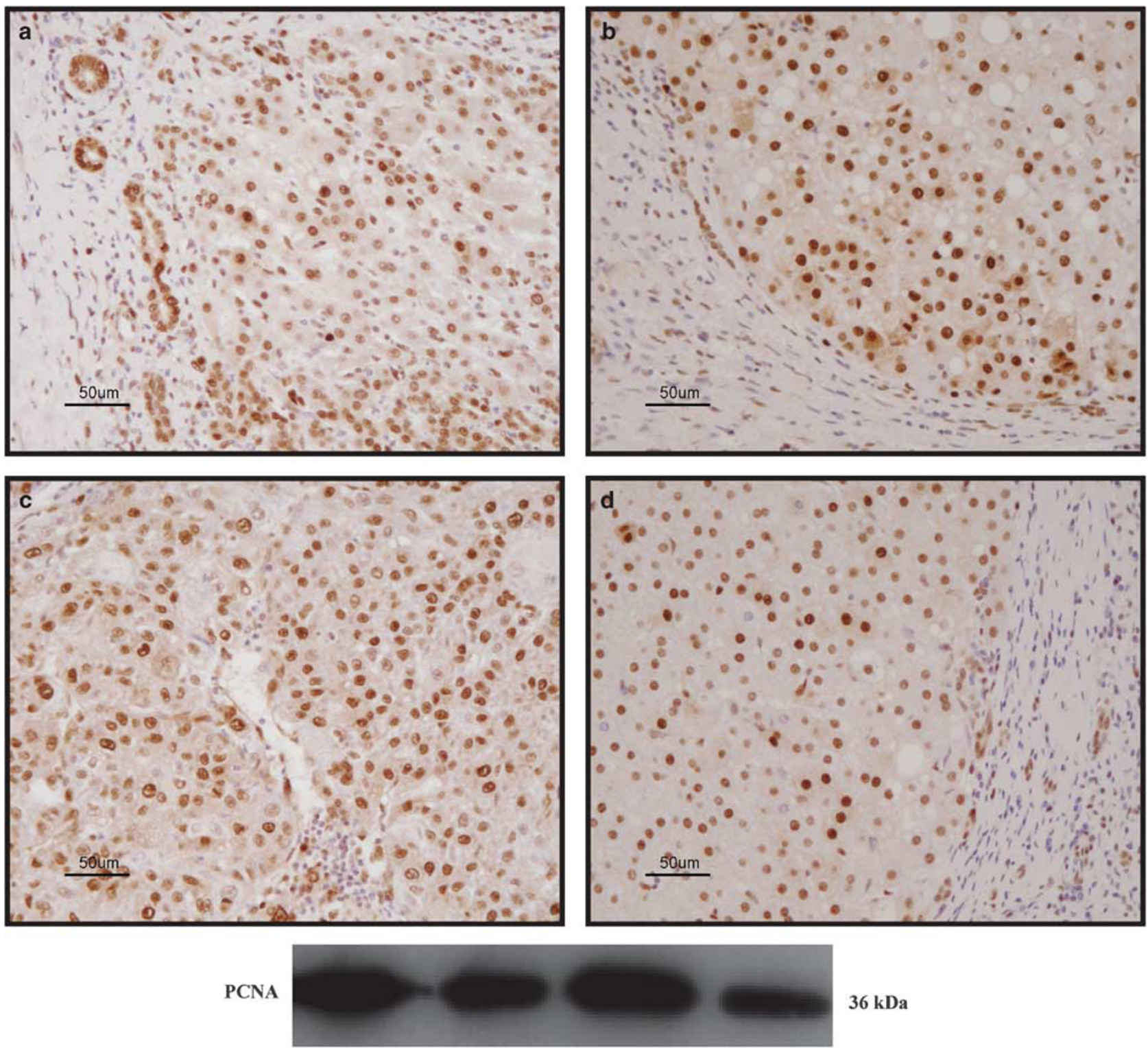

36 kDa

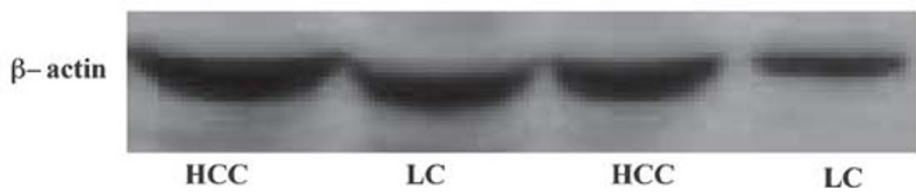

$46 \mathrm{kDa}$

Figure 9 Upper panel: PCNA immunostaining. PCNA immunoreactivity in HCCs (a, $\mathbf{c})$ relative to adjacent cirrhotic tissues (b, d). The sections (haematoxylin stained) depict representative examples of HCC showing PCNA expression pattern 1 (a, b) and pattern 2 (c, d). Lower panel: PCNA immunolabelling. Protein levels of PCNA examined by western blot analysis in the same two cases. HCC displaying PCNA expression pattern 1 (lane 1 ) as well as PCNA expression pattern 2 (lane 3) compared to the surrounding cirrhotic liver (lanes 2 and 4). $\beta$-Actin was analysed to rule out differences in protein loading. Abbreviation: LC, matched liver cirrhosis.

SDS-PAGE coupled with WB analysis ${ }^{42}$ (PC10 monoclonal and C-20 polyclonal anti-PCNA antibodies), the same results were obtained and no additional PCNA spots were detected.

The variant PCNA isoforms detected, including ubiquitylated and phosphorylated ones, might be regarded as a part of a continuum that extends from benign to malignant tissue, due to the increasing DNA synthesis and repair activity in cancer cells. It also seems plausible that distinct pools of PCNA might act simultaneously and in concert, to accomplish different roles within different metabolic pathways, as recently suggested. ${ }^{12}$ Alternatively, PCNA may shift from acidic to basic isoforms through the cell cycle phases and the 

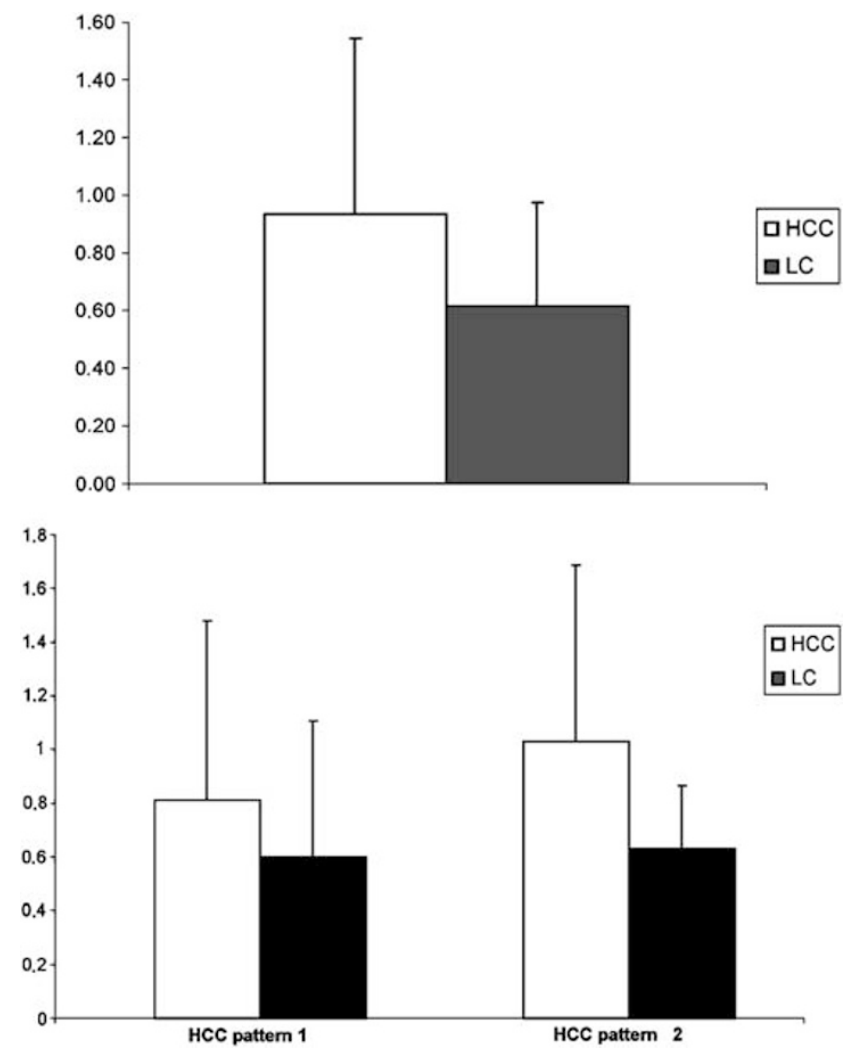

Figure 10 Comparative analysis of PCNA total protein amount detected by western blot in tissue samples. Upper panel: PCNA protein levels in HCCs relative to adjacent cirrhotic tissues. Lower panel: HCCs displaying PCNA expression pattern 1 and 2 compared to surrounding cirrhosis. PCNA total expression resulted similar in HCC (both PCNA expression patterns 1 and 2) and cirrhosis.

relative amounts of the different isoforms may vary during the cell cycle.

Lastly, after DNAse-I treatment, performed in order to release the PCNA detergent-insoluble fraction to verify if one or more of the basic isoforms previously detected in neoplastic samples were chromatin bound, only an acidic monomeric PCNA was observed. These data suggest that either DNA-bound PCNA post-translational modifications are too low to be detected by this kind of analysis or modified isoforms are spontaneously hydrolysed by the procedure of DNAse-I treatment, leaving an unmodified form.

The need to identify new diagnostic and prognostic HCC biomarker is still urgent. This study demonstrates that, by combining 2D-PAGE with WB analysis, it is possible to detect two main PCNA expression patterns in human liver tumours and cell lines, as well as PCNA isoforms specifically expressed in neoplastic samples. In PCNA expression pattern 1, at least three different main acidic forms and a basic isoform of PCNA were detected. A PCNA ubiquitylated form also is demonstrated in this expression patter. In pattern 2, PCNA was present in an acidic form associated with several basic phosphorylated isoforms. Most notably, in none of cirrhotic tissues was a PCNA basic spot was detected. These data show that PCNA is differently expressed in HCC and cirrhotic tissues, in terms of structure, isoforms and post-translational modifications, strongly implicating functional alterations in PCNA in the hepatocancerogenetic process. Future in vitro experiments will hopefully provide further information on the functional consequences of PCNA modifications, first of all ubiquitylation and phosphorylation, in the development of HCC.

Supplementary Information accompanies the paper on the Laboratory Investigation website (http://www.laboratoryinvestigation.org)

\section{ACKNOWLEDGEMENT}

This work was supported by funds from Fondazione Carisbo, Bologna.

\section{DUALITY OF INTEREST}

None declared.

1. Llovet JM, Burroughs A, Bruix J. Hepatocellular carcinoma. Lancet 2003:362:1907-1917.

2. Scherman M. Alpha feto protein: an obituary. J Hepatol 2001;34: 603-605.

3. Nagai $H$, Pineau $P$, Tiollais $P$, et al. Comprehensive allelotyping of human hepatocellular carcinoma. Oncogene 1997;14:2927-2933.

4. Tsopanoumichalou $M$, Kouroumalis E, Ergazaki $M$, et al. Loss of heterozygosity and microsatellite instability in human non-neoplastic hepatic lesions. Liver 1999;19:305-311.

5. Yeh SH, Chen PJ, Shau WY, et al. Chromosomal allelic imbalance evolving from liver cirrhosis to hepatocellular carcinoma. Gastroenterology 2001;121:699-709.

6. Berwick M, Vineis P. Markers of DNA repair and susceptibility to cancer in humans: an epidemiologic review. J Natl Cancer Inst 2000;92: 874-897.

7. Rouse J, Jackson SP. Interfaces between the detection, signaling, and repair of DNA damage. Science 2002;297:547-551.

8. Tsurimoto T. PCNA binding proteins. Front Biosci 1999;4:D849-D858.

9. Kelman Z. PCNA: structure, functions and interactions. Oncogene 1997; 14:629-640.

10. Prosperi E. Multiple roles of the proliferating cell nuclear antigen: DNA replication, repair and cell cycle control. Prog Cell Cycle Research 1997:3:193-210.

11. Maga G, Hubscher U. Proliferating cell nuclear antigen (PCNA): a dancer with many partners. J Cell Sci 2003;116:3051-3060.

12. Prosperi $E$. The fellowship of the ring: distinct pools of proliferating cell nuclear antigen at work. FASEB J 2006;20:833-837.

13. Celis JE, Celis A. Cell cycle-dependent variations in the distribution of the nuclear protein cyclin proliferating cell nuclear antigen in cultured cells: subdivision of S-phase. Proc Natl Acad Sci USA 1985;82: 3262-3266.

14. Bravo R, Macdonald-Bravo H. Changes in the nuclear distribution of cyclin (PCNA) but not its synthesis depend on DNA replication. EMBO J 1985;4:655-661.

15. Bravo R, Macdonald Bravo H. Existence of two populations of cyclin/ proliferating cell nuclear antigen during the cell cycle: association with DNA replication sites. J Cell Biol 1987;105:1549-1554.

16. Mathews MB, Bernstein RM, Franza Jr BR, et al. Identity of the proliferating cell nuclear antigen and cyclin. Nature 1984;309:374-376.

17. Jonsson ZO, Hubscher U. Proliferating cell nuclear antigen: more than a clamp for DNA polymerases. Bioessays 1997;19:967-975.

18. Loor $G$, Zhang $S J$, Zhang $P$, et al. Identification of DNA replication and cell cycle proteins that interact with PCNA. Nucleic Acids Res 1997:25:5041-5046.

19. Prosperi E, Scovassi Al, Stivala LA, et al. Proliferating cell nuclear antigen bound to DNA synthesis sites: phosphorylation and association with cyclin D1 and cyclin A. Exp Cell Res 1994;215:257-262.

20. Wang SC, Nakajima Y, Yu YL, et al. Tyrosine phosphorylation controls PCNA function through protein stability. Nat Cell Biol 2006;8: 1359-1368. 
21. Bravo R, Celis JE. Changes in the nuclear distribution of cyclin (PCNA) during S-phase are not triggered by post-translational modifications that are expected to moderately affect its charge. FEBS Lett 1985;182:435-440.

22. Naryzhny SN, Lee $\mathrm{H}$. The post-translational modifications of proliferating cell nuclear antigen: acetylation, not phosphorylation, plays an important role in the regulation of its function. J Biol Chem 2004;279:20194-20199.

23. Hoelz DJ, Arnold RJ, Dobrolecki LE, et al. The discovery of labile methyl esters on proliferating cell nuclear antigen by MS/MS. Proteomics 2006;6:4808-4816.

24. Hoege C, Pfander B, Moldovan GL, et al. RAD6-dependent DNA repair is linked to modification of PCNA by ubiquitin and SUMO. Nature 2002:419:135-141.

25. Haracska L, Torres-Ramos CA, Johnson RE, et al. Opposing effects of ubiquitin conjugation and SUMO modification of PCNA on replicational bypass of DNA lesions in Saccharomyces cerevisiae. Mol Cell Biol 2004;24:4267-4274.

26. Haracska L, Unk I, Prakash L, et al. Ubiquitylation of yeast proliferating cell nuclear antigen and its implications for translesion DNA synthesis. Proc Natl Acad Sci USA 2006;103:6477-6482.

27. Kannouche PL, Lehmann AR. Ubiquitination of PCNA and the polymerase switch in human cells. Cell Cycle 2004;3:1011-1013.

28. Ulrich HD. How to activate a damage-tolerant polymerase: consequences of PCNA modifications by ubiquitin and SUMO. Cell Cycle 2004;3:15-18.

29. Ulrich HD. Deubiquitinating PCNA: a downside to DNA damage tolerance. Nat Cell Biol 2006;8:303-305.

30. Henderson DS, Wiegand UK, Norman DG, et al. Mutual correction of faulty PCNA subunits in temperature-sensitive lethal mus209 mutants of Drosophila melanogaster. Genetics 2000;154:1721-1733.

31. Naryzhny SN, Zhao H, Lee H. Proliferating cell nuclear antigen (PCNA) may function as a double homotrimer complex in the mammalian cell. J Biol Chem 2005;280:13888-13894.

32. Naryzhny SN, Desouza LV, Siu KW, et al. Characterization of the human proliferating cell nuclear antigen physico-chemical properties: aspects of double trimer stability. Biochem Cell Biol 2006;84:669-676.

33. Bechtel PE, Hickey RJ, Schnaper L, et al. A unique form of proliferating cell nuclear antigen is present in malignant breast cells. Cancer Res 1998;58:3264-3269.

34. Malkas LH, Herbert BS, Abdel-Aziz W, et al. A cancer-associated PCNA expressed in breast cancer has implications as a potential biomarker. Proc Natl Acad Sci USA 2006;103:19472-19477.
35. Kawakita N, Seki S, Sakaguchi H, et al. Analysis of proliferating hepatocytes using a monoclonal antibody against proliferating cell nuclear antigen/cyclin in embedded tissues from various liver diseases fixed in formaldehyde. Am J Pathol 1992;140:513-520.

36. Gramantieri L, Trere $D$, Chieco $P$, et al. In human hepatocellular carcinoma in cirrhosis proliferating cell nuclear antigen (PCNA) is involved in cell proliferation and cooperates with P21 in DNA repair. J Hepatol 2003;39:997-1003.

37. Edmondson HA, Steiner PE. Primary carcinoma of the liver: a study of 100 cases among 48,900 necropsies. Cancer 1954;7:462-503.

38. Laemmli UK. Cleavage of structural proteins during the assembly of the head of bacteriophage T4. Nature 1970;227:680-685.

39. Herbert B, Galvani M, Hamdan M, et al. Reduction and alkylation of proteins in preparation of two-dimensional map analysis: why, when, and how? Electrophoresis 2001;22:2046-2057.

40. Sadaie MR, Mathews MB. Immunochemical and biochemical analysis of the proliferating cell nuclear antigen (PCNA) in HeLa cells. Exp Cell Res 1986;163:423-433.

41. Shevchenko A, Wilm M, Worm O, et al. Mass spectrometric sequencing of protein from silver stained polyacrilamide gels. Anal Chem 1996;68:850-858.

42. Naryzhny SN, Lee H. Observation of multiple isoforms and specific proteolysis patterns of proliferating cell nuclear antigen in the context of cell cycle compartments and sample preparation. Proteomics 2003:3:930-936.

43. Schivakumar CV, Brown DR, Deb S, et al. Wild-type human p53 transactivates the human proliferating cell nuclear antigen promoter. Mol Cell Biol 1995; 15:6785-6793.

44. Bauer GA, Burgers PM. The yeast analog of mammalian cyclin/ proliferating-cell nuclear antigen interacts with mammalian DNA polymerase delta. PNAS 1988;85:7506-7510.

45. Yao N, Turner J, Kelman Z, et al. Clamp loading, unloading and intrinsic stability of the PCNA, beta and gp45 sliding clamps of human, E. coli and T4 replicases. Genes Cell 1996;1:101-113.

46. Barbour L, Xiao W. Regulation of alternative replication bypass pathways at stalled replication forks and its effects on genome stability: a yeast model. Mutat Res 2003;532:137-155.

47. Zhuo S, Clemens JC, Hakes DJ, et al. Expression, purification, crystallization, and biochemical characterization of a recombinant protein phosphatise. J Biol Chem 1993;268:17754-17761.

48. Hunter T. Protein kinases and phosphatases: the yin and yang of protein phosphorylation and signalling. Cell 1995;80: 225-236. 